\title{
Chestnut bur extracts as antioxidants: optimization of the extraction stage
}

\author{
G. Vázquez, A. Fernández-Agulló, M. S. Freire, G. Antorrena \\ \& J. González-Álvarez \\ Department of Chemical Engineering, \\ University of Santiago de Compostela, Spain
}

\begin{abstract}
In this work the exploitation and subsequent valorization of chestnut bur, a forest waste product from chestnut processing in the food industry, is proposed. The experimental design and response surface methodology were applied to optimize the extraction of chestnut bur polyphenols with aqueous methanol. An incomplete factorial design $3^{3}$ was applied to study the influence of temperature $\left(25-50-75^{\circ} \mathrm{C}\right)$, time $(30-75-120 \mathrm{~min})$ and methanol concentration $(50-70-90 \%$ by weight) on extraction yield, extract total phenols content (using the FolinCiocalteu method), FRAP antioxidant activity, DPPH and ABTS radical scavenging activity. Temperatures in the range $60-75^{\circ} \mathrm{C}$, an extraction time of 75 min and $\mathrm{MeOH}$ concentrations in the range $50-60 \%$ led not only to extracts with high antioxidant activity (30.89-36.32 g GAE/100 g extract for the total phenol content, 2220-2292 nmol AAE/mg extract for FRAP antioxidant activity; 3.22$3.40 \mathrm{mmol} \mathrm{TRE} / \mathrm{g}$ extract for the DPPH assay and 3.26-3.45 mmol TRE/g extract for the ABTS assay), but also to high extraction yields (15.06-19.30\%). Chestnut bur extracts were analysed by RP-HPLC-ESI-TOF, which revealed the presence of gallic acid esters of glucose, ellagic acid and small proportions of quercetin and quercetin-3 $\beta$-D-glucoside.
\end{abstract}

Keywords: chestnut bur, antioxidant activity, phenolic compounds, experimental design, response surface methodology, RP-HPLC-ESI-TOF.

\section{Introduction}

The growing interest in the research on natural antioxidants has been promoted by the need to find natural substitutes for synthetic antioxidants that have been 
used since the early 20th century, as they are suspected of being responsible for liver damage and carcinogenesis in laboratory animals [1]. The beneficial effects derived from phenolic compounds, such as their anticarcinogenic, antimutagenic and cardioprotective activities have been attributed to their antioxidant activity $[2,3]$. The investigations have been directed towards the obtaining of natural antioxidants from vegetable sources, especially from the inexpensive waste products from the food, forest or agricultural industries. Several plant materials have been studied: plants and agri-industrial by-products [3], nuts and their byproducts, such as almond hulls [4], hazelnuts [1], Geviina avellana hulls [5], chestnut fruits [6] and chestnut shells $[6,7]$, and tree materials, such as pine sawdust [4], pine bark [8] and eucalyptus bark [7].

Approximately $7000 \mathrm{t} / \mathrm{year}$ of chestnuts (Castanea sativa) are processed in the Galician (NW of Spain) food industry to produce derivates such as marronglacé, chestnut purée, etc. Chestnut shell and bur are waste products generated in this process. The former, whose exploitation has been also proposed by the authors [7], is separated in the food factory whereas the bur usually remains in the woodland after fruit harvesting and promotes the proliferation of certain insect larvae, which causes damages to crops. The potential of chestnut bur as a source of natural antioxidants has been previously studied by the authors using water and various organic solvents and the best results regarding extraction yield and extract antioxidant activity were obtained using water and methanol [9]. In this work, the experimental design and response surface methodologies were applied to optimize the extraction of chestnut bur polyphenols with aqueous methanol.

\section{Materials and methods}

\subsection{Extraction and concentration}

Chestnut bur was collected in a chestnut plantation in Santiago de Compostela (Galicia, NW Spain). It was air-dried till equilibrium humidity, ground and the fraction of particle size between 0.1 and $2 \mathrm{~mm}$ was selected. The extraction experiments were carried out using 1-L Pyrex glass flask in an orbital shaker at a solid/liquid ratio of $1 / 10(\mathrm{w} / \mathrm{w})$. The extracted material was recovered by vacuum filtration and the solvent was evaporated in a Büchi R-210 rotavapor. The extraction yield was calculated as the weight loss percentage of the starting material. The extraction operational conditions used are shown in table 1.

\subsection{Total phenol content}

Total phenols content was determined by the Folin-Ciocalteu method: to $0.5 \mathrm{~mL}$ of an aqueous solution of the extract, $2.5 \mathrm{~mL}$ of Folin-Ciocalteu reactive, previously diluted with water $(1: 10, \mathrm{v} / \mathrm{v})$, and $2 \mathrm{~mL}$ of a $75 \mathrm{~g} / \mathrm{L} \mathrm{Na}_{2} \mathrm{CO}_{3}$ aqueous solution were added. The mixture was kept $5 \mathrm{~min}$ at $50^{\circ} \mathrm{C}$ and, after cooling, the absorbance at $760 \mathrm{~nm}$ was measured. The phenols content was expressed as 
g gallic acid equivalent (GAE)/100 g extract (on dried basis). The analyses were carried out in triplicate and the results averaged.

\subsection{Antioxidant activity}

\subsubsection{Ferric reducing antioxidant power (FRAP)}

The FRAP assay was done as follows: $0.1 \mathrm{~mL}$ of an aqueous solution of the extracts were transferred to a test tube and $3.0 \mathrm{~mL}$ of freshly prepared FRAP reagent $(25 \mathrm{~mL}$ of acetate buffer, $300 \mathrm{mmol} / \mathrm{L}, \mathrm{pH}=3.6 ; 2.5 \mathrm{~mL}$ of $10 \mathrm{mmol}$ TPTZ (2,4,6-tripyridyl-s-triazine) in $40 \mathrm{mmol} / \mathrm{L} \mathrm{HCl} ; 2.5 \mathrm{~mL}$ of $20 \mathrm{mmol} / \mathrm{L}$ $\mathrm{FeCl}_{3} .6 \mathrm{H}_{2} \mathrm{O}$ ) were added. The absorbance was recorded after $5 \mathrm{~min}$ at $593 \mathrm{~nm}$. The relative activities of samples were expressed as nmol ascorbic acid equivalent (AAE) per mg extract (on dried basis). The analyses were carried out in triplicate and the results averaged.

\subsubsection{DPPH radical-scavenging activity}

Aqueous solutions of chestnut bur extracts $(8-240 \mu \mathrm{g} / \mathrm{mL})$ were prepared. The extract solution $(0.3 \mathrm{~mL})$ was mixed with $2.7 \mathrm{~mL}$ of a freshly prepared DPPH (1,1-diphenyl-2-picrylhydrazyl) solution $\left(6.10^{-5} \mathrm{M}\right.$ in $80 \%$ methanol). The mixture was shaken vigorously and left to stand for $20 \mathrm{~min}$ in the dark at room temperature. Then the absorbance was read at $517 \mathrm{~nm}$. The radical-scavenging activity (RSA) was determined as $\% R S A=100\left(A_{0}-A_{s}\right) / A_{0}$, where $A_{s}$ is the absorbance of the extract solution and $\mathrm{A}_{0}$ is the absorbance of a control solution prepared without extracts. The Trolox equivalent of the extracts (TRE) was calculated and expressed as mmol Trolox equivalent (TRE) per g extract (on dried basis).

\subsubsection{ABTS radical-scavenging activity}

ABTS (2,2'-Azinobis-3-ethylbenzothiazoline-6-sulfonic acid) radical cation $\left(\right.$ ABTS $\left.^{\circ+}\right)$ was produced by reacting an ABTS solution $(7 \mathrm{mM})$ with potassium persulfate $(2.45 \mathrm{mM})$ for $16 \mathrm{~h}$ in the dark at room temperature. The ABTS $^{\circ+}$ solution was diluted with water to an absorbance of 0.70 at $734 \mathrm{~nm}$. Aqueous solutions of chestnut bur extracts $(20-960 \mu \mathrm{g} / \mathrm{mL})$ were prepared. The extract solution $(25 \mu \mathrm{L})$ was mixed with the ABTS $^{\circ+}$ solution $(2.5 \mathrm{~mL})$ and after 6 min in the dark at room temperature the absorbance was read at $734 \mathrm{~nm}$. The RSA of the extract solutions and the extract TRE were calculated as indicated in the DPPH method.

\subsection{RP-HPLC-ESI-TOF mass spectrometry}

Chestnut bur extracts were evaluated using an Agilent Technologies 1100 HPLC and a Bruker Microtof ESI-TOF instrument. Tannins were separated using a Zorbax Eclipse XDB-C18 $5 \mu \mathrm{m}(4.6 \times 150 \mathrm{~mm})$ column and a binary gradient of $2 \%$ acetic acid for mobile phase $\mathrm{A}$ and $0.5 \%$ acetic acid in water/acetonitrile $(1: 1, \mathrm{v} / \mathrm{v})$ for mobile phase $\mathrm{B}$ at a flow rate of $1 \mathrm{~mL} / \mathrm{min}$ and a postcolumn split of $1 / 0.2 \mathrm{~mL} / \mathrm{min}$. The linear gradient was from 10 to $55 \% \mathrm{~B}$ from 0 to $50 \mathrm{~min}$, from 55 to $100 \% \mathrm{~B}$ from 50 to $60 \mathrm{~min}$ and from 100 to $10 \% \mathrm{~B}$ from 60 to 65 
min. The mass spectrometry analysis was performed in negative ion mode. The samples were dissolved in water to a concentration in the range 100-200 ppm.

\subsection{Design of experiments}

An incomplete factorial design $3^{3}$ was applied to study the influence of temperature $\left(\mathrm{x}_{1}, 25-50-75^{\circ} \mathrm{C}\right)$, time $\left(\mathrm{x}_{2}, 30-75-120 \mathrm{~min}\right)$ and $\mathrm{MeOH}$ concentration $\left(\mathrm{x}_{3}, 50-70-90 \%\right)$ on several dependent variables. The solid/liquid ratio was kept constant at $1 / 10(\mathrm{w} / \mathrm{w})$. The experimental design selected was compound for twelve experiments and three replicates in the central point.

The dependent variables $\left(\mathrm{Y}_{\mathrm{j}}\right)$ selected were the extraction yield $\left(\mathrm{Y}_{1}, \mathrm{~g}\right.$ extract/100 g chestnut bur), total phenols content $\left(\mathrm{Y}_{2}\right.$, g gallic acid equivalents (GAE)/100 g extract) together with several variables related with the antioxidant activity of the extracts: FRAP antioxidant activity $\left(\mathrm{Y}_{3}, \mathrm{nmol}\right.$ ascorbic acid equivalents (AAE)/mg extract), DPPH radical-scavenging activity ( $\mathrm{Y}_{4} \mathrm{mmol}$ Trolox equivalent (TRE)/g extract) and ABTS radical-scavenging activity $\left(\mathrm{Y}_{5}\right.$ mmol Trolox equivalent (TRE)/g extract).

Experimental results were analysed by linear regression using the backwards elimination method (SPSS 15.0 software) and fitted to polynomials of the form:

$$
\begin{gathered}
Y_{j}=a_{0 j}+a_{1 j} x_{1}^{*}+a_{2 j} x_{2}^{*}+a_{3 j} x_{3}^{*}+a_{12 j} x_{1}^{*} x_{2}^{*}+a_{13 j} x_{1}^{*} x_{3}^{*}+a_{23 j} x_{2}^{*} x_{3}^{*} \\
+a_{11 j} x_{1}^{* 2}+a_{22 j} x_{2}^{* 2}+a_{33 j} x_{3}^{* 2}
\end{gathered}
$$

where $\mathrm{x}_{1}{ }^{*}, \mathrm{x}_{2}{ }^{*}$ and $\mathrm{x}_{3}{ }^{*}$ are the independent variables coded at three levels -1 (lower limit), 0 (central point) and +1 (upper limit).

The statistical analysis was performed using the analysis of variance (ANOVA) including the F-ratio, which established the global model significance and the determination coefficients $\mathrm{R}^{2}$ and adjusted $\mathrm{R}^{2}$. In addition, experimental and predicted values for each dependent variable were compared. The significant factors affecting each dependent variable were selected according to the Student t test establishing a $90 \%$ confidence level.

\section{Results and discussion}

\subsection{Extraction optimization}

Table 1 shows the coded values of the independent variables for each experiment and the experimental results obtained for extraction yield and extract properties according to the $3^{3}$ factorial experimental design planned.

The coefficients of the significant models, eqn (1), are presented in table 2 together with the correlation parameters and model significance. Figure 1 shows, as an example, the high correlation between the experimental values and those predicted by the model for the extraction yield $\left(\mathrm{Y}_{1}\right)$. 
Table 1: Experimental results for extraction yield and extract properties according to the $3^{3}$ factorial experimental design.

\begin{tabular}{|c|c|c|c|c|c|c|c|c|}
\hline EXP & $\mathrm{x}_{1}{ }^{7}$ & $\mathrm{x}_{2}{ }^{*}$ & $\mathrm{x}_{3}$ & $\mathrm{Y}_{1}$ & $\mathrm{Y}_{2}$ & $\mathrm{Y}_{3}$ & $\mathrm{Y}_{4}$ & $\mathrm{Y}_{5}$ \\
\hline 1 & -1 & -1 & 0 & 11.52 & 19.93 & 1254 & 1.93 & 1.97 \\
\hline 2 & -1 & 0 & -1 & 10.52 & 26.28 & 1832 & 2.50 & 2.67 \\
\hline 3 & -1 & 0 & 1 & 13.63 & 16.88 & 952 & 1.74 & 1.48 \\
\hline 4 & -1 & 1 & 0 & 12.95 & 24.73 & 1482 & 2.17 & 2.15 \\
\hline 5 & 0 & -1 & -1 & 11.90 & 29.74 & 1770 & 2.98 & 2.96 \\
\hline 6 & 0 & -1 & 1 & 13.05 & 17.66 & 1011 & 2.09 & 1.37 \\
\hline 7 & 0 & 1 & -1 & 13.07 & 33.76 & 2261 & 3.42 & 3.80 \\
\hline 8 & 0 & 1 & 1 & 14.71 & 20.51 & 1297 & 2.24 & 1.59 \\
\hline 9 & 1 & -1 & 0 & 17.62 & 28.33 & 1866 & 2.65 & 2.55 \\
\hline 10 & 1 & 0 & -1 & 19.05 & 33.82 & 2151 & 2.85 & 3.04 \\
\hline 11 & 1 & 0 & 1 & 18.48 & 29.68 & 1567 & 2.74 & 1.95 \\
\hline 12 & 1 & 1 & 0 & 19.70 & 35.98 & 2050 & 3.24 & 3.21 \\
\hline 13 & 0 & 0 & 0 & 13.53 & 29.43 & 2183 & 3.24 & 3.07 \\
\hline 14 & 0 & 0 & 0 & 15.14 & 28.26 & 2034 & 3.18 & 2.89 \\
\hline 15 & 0 & 0 & 0 & 14.60 & 21.99 & 1764 & 3.18 & 2.90 \\
\hline \multirow{2}{*}{\multicolumn{3}{|c|}{ Independent variable }} & \multicolumn{6}{|c|}{ Levels } \\
\hline & & & \multicolumn{2}{|c|}{-1} & \multicolumn{2}{|c|}{0} & \multicolumn{2}{|c|}{+1} \\
\hline \multicolumn{3}{|c|}{$\mathrm{x}_{1}$, Temperature $\left({ }^{\circ} \mathrm{C}\right)$} & \multicolumn{2}{|c|}{25} & \multicolumn{2}{|c|}{50} & \multicolumn{2}{|c|}{75} \\
\hline \multicolumn{3}{|c|}{$\mathrm{x}_{2}$, Time $(\min )$} & \multirow{2}{*}{\multicolumn{2}{|c|}{30}} & \multirow{2}{*}{\multicolumn{2}{|c|}{$\frac{75}{70}$}} & \multicolumn{2}{|c|}{120} \\
\hline \multicolumn{3}{|c|}{$\mathrm{x}_{3}, \mathrm{MeOH}(\%)$} & 50 & & 70 & & \multicolumn{2}{|c|}{90} \\
\hline
\end{tabular}

$\mathrm{Y}_{1}$, extraction yield $\left(\mathrm{g}\right.$ extract/100 g bur): $\mathrm{Y}_{2}$, total phenols content $(\mathrm{g}$ GAE/100 g extract); antioxidant activity: $\mathrm{Y}_{3}$, FRAP (nmol AAE/mg extract); $\mathrm{Y}_{4}$, DPPH (mmol TRE/g extract); $\mathrm{Y}_{5}$, ABTS (mmol TRE/g extract).

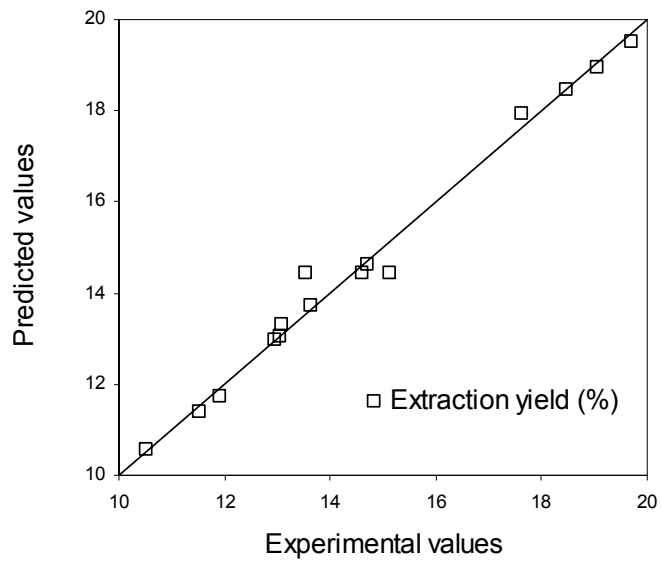

Figure 1: Experimental versus predicted values for chestnut bur extraction yield. 
Table 2: $\quad$ Coefficients of the significant models, eqn (1), and model statistical parameters.

\begin{tabular}{|c|c|c|c|c|c|}
\hline & $\mathrm{Y}_{1}$ & $\mathrm{Y}_{2}$ & $\mathrm{Y}_{3}$ & $\mathrm{Y}_{4}$ & $\mathrm{Y}_{5}$ \\
\hline $\mathrm{a}_{0}$ & 14.423 & 26.465 & 1993.783 & 3.200 & 2.849 \\
\hline $\mathrm{a}_{1}$ & 3.279 & 4.999 & 264.365 & 0.393 & 0.310 \\
\hline $\mathrm{a}_{2}$ & 0.793 & 2.415 & 148.421 & 0.178 & 0.238 \\
\hline $\mathrm{a}_{3}$ & 0066 & -4.859 & -398.479 & -0.368 & -0.760 \\
\hline $\mathrm{a}_{12}$ & $\mathrm{NS}$ & $\mathrm{NS}$ & $\mathrm{NS}$ & $\mathrm{NS}$ & $\mathrm{NS}$ \\
\hline $\mathrm{a}_{13}$ & -0.920 & $\mathrm{NS}$ & $\mathrm{NS}$ & $\mathrm{NS}$ & $\mathrm{NS}$ \\
\hline $\mathrm{a}_{23}$ & $\mathrm{NS}$ & $\mathrm{NS}$ & $\mathrm{NS}$ & $\mathrm{NS}$ & $\mathrm{NS}$ \\
\hline $\mathrm{a}_{11}$ & 1.631 & $\mathrm{NS}$ & -144.978 & -0.464 & -0.301 \\
\hline $\mathrm{a}_{22}$ & -0.607 & $\mathrm{NS}$ & -186.000 & -0.239 & $\mathrm{NS}$ \\
\hline $\mathrm{a}_{33}$ & -0.634 & $\mathrm{NS}$ & -223.230 & -0.279 & -0.341 \\
\hline $\mathrm{R}^{2}$ & 0.986 & 0.862 & 0.938 & 0.909 & 0.909 \\
\hline Adj. ${ }^{2}$ & 0.972 & 0.825 & 0.891 & 0.841 & 0.858 \\
\hline $\mathrm{SD}$ & 0.480 & 2.516 & 139.631 & 0.215 & 0.270 \\
\hline Sig. & 0.000 & 0.000 & 0.000 & 0.001 & 0.000 \\
\hline
\end{tabular}

NS: non-significant coefficient for a $90 \%$ confidence level. SD: standard deviation. Sig: model significance. $\mathrm{Y}_{1}$, extraction yield ( $\mathrm{g}$ extract $/ 100 \mathrm{~g}$ chestnut bur on dried basis): $\mathrm{Y}_{2}$, total phenols content (g GAE/100 g extract); antioxidant activity: $\mathrm{Y}_{3}$, FRAP (nmol AAE/mg extract); $\mathrm{Y}_{4}, \mathrm{DPPH}$ (mmol TRE/g extract); $\mathrm{Y}_{5}$, ABTS (mmol TRE/g extract).

For all the dependent variables analysed, the three independent variables were significant. Temperature $\left(\mathrm{x}_{1}\right)$ and $\mathrm{MeOH}$ concentration $\left(\mathrm{x}_{3}\right)$ were the most significant variables in all cases, except for the extraction yield, which depended mainly on temperature $\left(\mathrm{x}_{1}\right)$ and its second order interaction $\left(\mathrm{x}_{1}{ }^{2}\right)$ followed by time $\left(\mathrm{x}_{2}\right)$.

The analysis of the response surfaces calculated for the dependent variables studied allowed selecting the optimal extraction conditions for obtaining extracts with high antioxidant activity together with high extraction yield.

The extraction yields obtained for methanol/water extractions of chestnut bur (10.52-19.70\%) were in the range obtained using the pure solvents in the preliminary study (11.05\% for methanol extracts and $21.20 \%$ for water extracts) [9] and significantly higher than those obtained for chestnut shell in a previous work (2.87\% for methanol extracts and $12.2 \%$ for water extracts) [7]. The experiments at the highest temperature essayed, $75^{\circ} \mathrm{C}$, led to the highest extraction yields.

Figure 2 shows the response surface for extraction yield in function of temperature and $\mathrm{MeOH}$ concentration at the intermediate value of time (75 $\mathrm{min})$. Extraction yield increased with increasing temperature and time and was nearly independent of $\mathrm{MeOH}$ concentration operating at temperatures above $55^{\circ} \mathrm{C}$. On the contrary, at temperatures below $55^{\circ} \mathrm{C}$, the higher the $\mathrm{MeOH}$ concentration, the higher the extraction yield. Moreover, the influence of temperature was greater operating at high temperature levels.

With respect to the extract properties as antioxidants, experiment 7 led to the highest DPPH and ABTS radical scavenging activities and FRAP antioxidant 
activity, whereas the highest extract total phenols content was obtained for experiment 12. The total phenols contents referred to the raw material were also calculated (2.30-7.09 g GAE/g oven-dried bur) and the highest value corresponded also to experiment 12. As shown, the results were of the same order as those encountered in the preliminary study for the pure solvents extracts (3.19 g GAE/g o.d. bur for methanol extracts and $7.99 \mathrm{~g} \mathrm{GAE} / \mathrm{g}$ o.d. bur for water extracts) [9], and higher than those obtained for chestnut shell extracts (0.93 g GAE/g o.d. shell for methanol extracts and $6.81 \mathrm{~g} \mathrm{GAE} / \mathrm{g}$ o.d. shell for water extracts) [7].

Total phenols content and antioxidant activity of the extracts, for the three methods used, increased with increasing extraction temperature and with decreasing $\mathrm{MeOH}$ concentration. As regards the influence of extraction time, all the extract properties increased with increasing time from 30 to $75 \mathrm{~min}$, however, further increases did not mean significant improvements. Then, $75 \mathrm{~min}$ was selected as the optimal extraction time, and the corresponding surface responses for total phenols content and FRAP, DPPH and ABTS antioxidant activities are shown in figure 3 as a function of temperature and $\mathrm{MeOH}$ concentration.

The highest extract total phenol content (figure 3a) was obtained operating at the highest temperature $\left(75^{\circ} \mathrm{C}\right)$ and the lowest $\mathrm{MeOH}$ concentration $(50 \%)$. With respect to extract antioxidant activity (figure $3 \mathrm{~b}-\mathrm{d}$ ) all the response surfaces showed a point of maximum response or stationary point, whose position depended on the essay used. Departing from this point, increasing or decreasing either the temperature or the $\mathrm{MeOH}$ concentration, decreased the extract antioxidant activity. In the case of the FRAP essay the maximum was located at the highest temperature $\left(75^{\circ} \mathrm{C}\right)$ and the lowest $\mathrm{MeOH}$ concentration $(50 \%)$. For the DPPH and ABTS essays a temperature of $60^{\circ} \mathrm{C}$ and a $\mathrm{MeOH}$ concentration of about 58 and $50 \%$, respectively, were the optimum conditions.

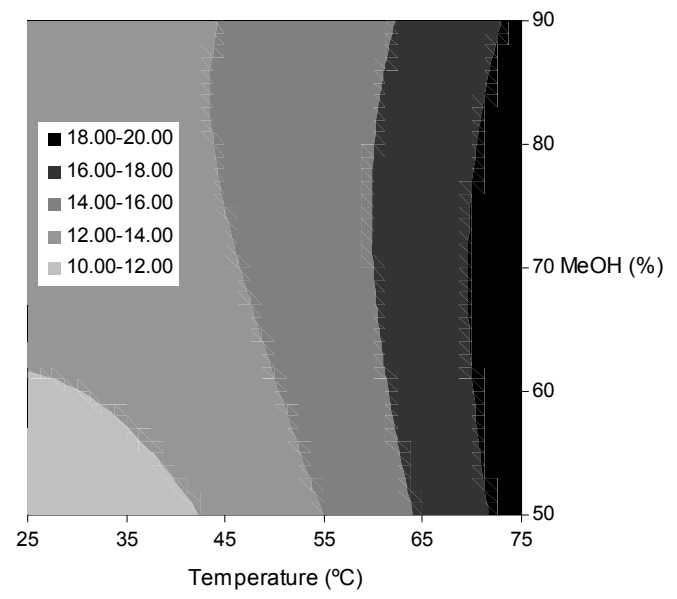

Figure 2: $\quad$ Response surface for extraction yield (\%) in function of methanol concentration and temperature for an extraction time of $75 \mathrm{~min}$. 

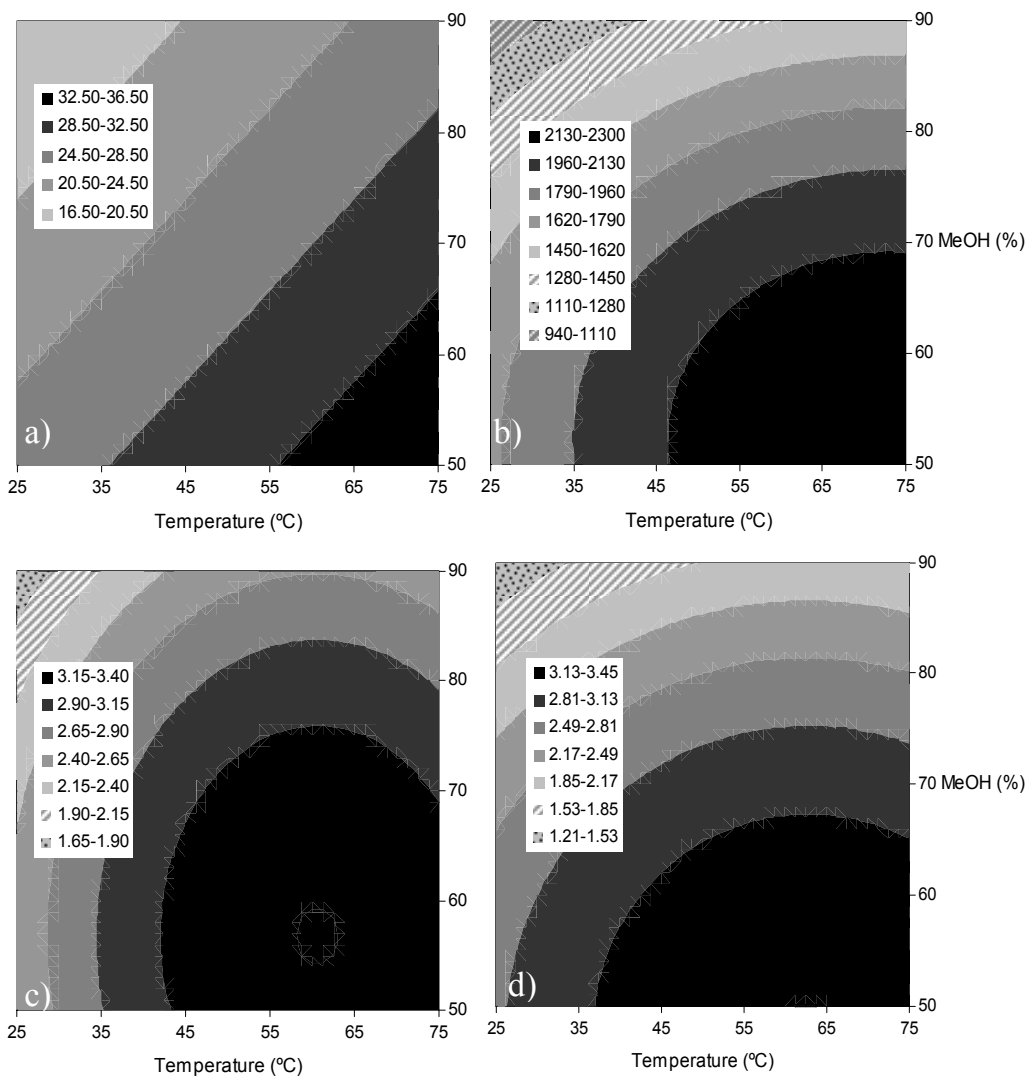

Figure 3: Response surface for a) total phenol content, b) FRAP antioxidant activity, c) DPPH radical scavenging activity and d) ABTS radical scavenging activity in function of methanol concentration and temperature for an extraction time of $75 \mathrm{~min}$.

Finally, analysing the results for all the dependent variables together, the following extraction operational conditions were selected to obtain high yields of chestnut bur extracts with high antioxidant activity: temperatures in the range 60$75^{\circ} \mathrm{C}$, an extraction time of $75 \mathrm{~min}$ and $\mathrm{MeOH}$ concentrations in the range 50$60 \%$. Under those conditions the values predicted for the dependent variables were as follows: $30.89-36.32 \mathrm{~g} \mathrm{GAE} / 100 \mathrm{~g}$ extract for the total phenol content, 2220-2292 nmol AAE/mg extract for the FRAP antioxidant activity, 3.22-3.40 $\mathrm{mmol} \mathrm{TRE} / \mathrm{g}$ extract for the DPPH assay, 3.26-3.45 mmol TRE/g extract for the ABTS assay and extraction yields from 15.06 to $19.30 \%$.

\subsection{Relationship between extracts properties}

In the preliminary study carried out [9] a linear relationship was found between extract total phenols content (TPC) and antioxidant activity. This kind of relationship has been also reported for extracts of other plant materials $[6,7]$. 
However, in the present work the results for total phenols content and antioxidant activity essays were less well correlated, as revealed the corresponding determination coefficients: $\mathrm{r}^{2}=0.7858$ for TPC and FRAP, $\mathrm{r}^{2}=0.6333$ for TPC and DPPH and $\mathrm{r}^{2}=0.6811$ for TPC and ABTS. On the contrary, as illustrated in figure 4 , a better correlation was found between DPPH and ABTS values and FRAP antioxidant activity $\left(\mathrm{r}^{2}=0.8097\right.$ and $\mathrm{r}^{2}=0.8913$, respectively).

\subsection{Characterization of chestnut bur extracts}

Reverse phase HPLC-ESI-TOF mass spectrometry was used to identify the compounds with potential antioxidant activity present in chestnut bur extracts. As an example, Figure 5 shows the HPLC chromatogram for the extract with the best antioxidant properties, the extract from experiment 7. Some phenolic compounds with demonstrated antioxidant properties were identified: gallic acid esters of glucose (mono-, di- and tri- galloyl glucoses), ellagic acid and small amounts of quercetin-3 $\beta$-D-glucoside and quercetin. Table 3 summarizes the characteristics of the identified peaks.

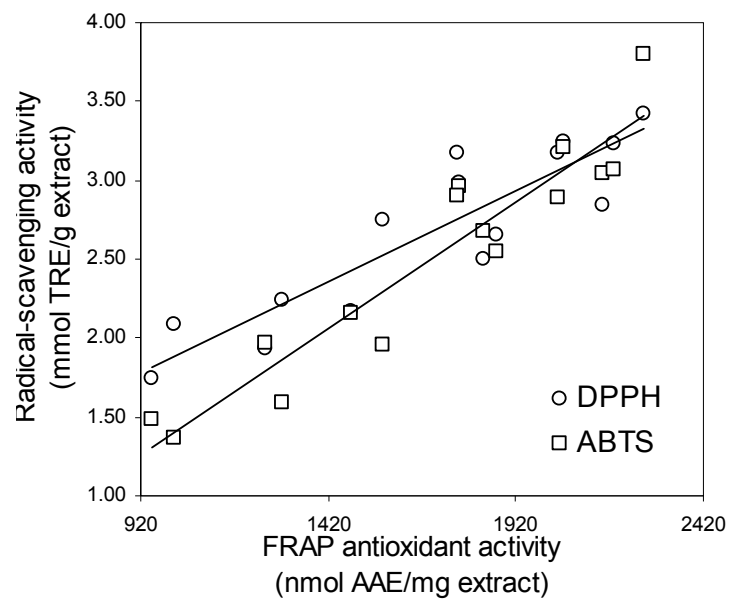

Figure 4: Correlation of DPPH and ABTS values and FRAP antioxidant activity.

Table 3: $\quad$ Phenolic compounds identified in chestnut bur extracts.

\begin{tabular}{|c|c|c|c|}
\hline Peak & $\mathrm{RT}(\min )$ & {$[\mathrm{M}-\mathrm{H}]^{-}(\mathrm{m} / \mathrm{z})$} & Compound \\
\hline 2 & 2.0 & $331 / 481 / 631$ & $\begin{array}{l}\text { Mono-, di- and tri } \\
\text { galloyl glucoses }\end{array}$ \\
\hline 3 & 26.5 & 301 & Ellagic acid \\
\hline 4 & 28.0 & $301 / 463$ & $\begin{array}{l}\text { Quercetin and quercetin-3 } \beta \text {-D- } \\
\text { glucoside }\end{array}$ \\
\hline
\end{tabular}

RT: retention time. 


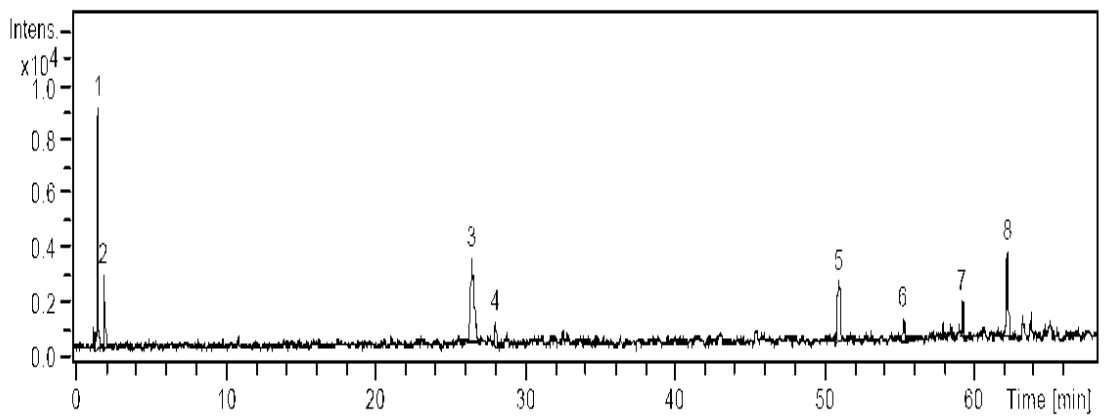

Figure 5: $\quad$ HPLC chromatogram of chestnut bur extract from experiment 7.

\section{Conclusions}

A factorial designed was applied to optimize the extraction of antioxidant phenolic compounds from chestnut bur using aqueous $\mathrm{MeOH}$ solutions. The operational conditions selected to obtain high yields of extracts with significant antioxidant properties were: temperatures in the range $60-75^{\circ} \mathrm{C}$, time of $75 \mathrm{~min}$ and $\mathrm{MeOH}$ concentrations in the range 50-60\%. Moderate linear correlations between FRAP, DPPH and ABTS antioxidant activity assays were found, whereas total phenols content and antioxidant activity were less well correlated. Finally, chestnut bur extracts were characterized as a mixture of gallic acid esters of glucose, ellagic acid and small proportions of quercetin and quercetin-3 $\beta$-Dglucoside, phenolic compounds with demonstrated antioxidant properties, together with some not identified compounds.

\section{Acknowledgements}

This work was funded by Ministerio de Ciencia e Innovación, FEDER funds and Plan E funds (CTQ2009-07539). Authors are also grateful to "Fundación Segundo Gil Dávila" for a research grant awarded to Adela Fernández Agulló.

\section{References}

[1] Contini, M., Baccelloni, S., Massantini, R., Anelli, G., Extraction of natural antioxidants from hazelnut (Corylus avellana L.) shell and skin wastes by long maceration at room temperature, Food Chem., 110, pp. 659-669, 2008.

[2] Madhavi, D.L., Despande, S.S., \& Salunke, D.K. Food antioxidants. Technological, toxicological and health perspectives. Marcel Dekker: New York, 1996.

[3] Balasundram, N, Sundram, K, \& Sundram, S., Phenolic compounds in plants and agri-industrial by-products: Antioxidant activity, ocurrence and potential uses. Food Chem., 99, pp. 191-203, 2006. 
[4] Pinelo, M., Rubilar, M., Sineiro, J., Núñez, M.J., Extraction of antioxidant phenolics from almond hulls (Prunus amygdalus) and pine sawdust (Pinus pinaster), Food Chem., 85, pp. 267-273, 2004.

[5] Moure, A., Franco, D., Sineiro, J., Dominguez, H., Núñez, M.J., Lema, J.M, Evaluation of Extracts from Gevuina avellana Hulls as Antioxidants, $J$. Agric. Food Chem,. 48, pp. 3890-3897, 2000.

[6] Barreira, J.C.M., Ferreira, I.C.F.R., Oliveira, M.B.P.P., Pereira, J.A., Antioxidant activities of the extracts from chestnut flower, leaf, skins and fruit, Food Chem., 107, pp. 1106-1113, 2008.

[7] Vázquez, G., Fontenla, E., Santos, J., Freire, M.S., González-Alvarez, J., Antorrena, G., Antioxidant activity and phenolic content of chestnut (Castanea sativa) shell and eucalyptus (Eucalyptus globulus) bark extracts, Ind. Crops Prod., 28, pp. 279-285, 2008.

[8] Weber, H., Hodges, A.E., Guthrie, J.R., O’Brien, B.M., Robaugh, D., Clarck, A.P., Harris, R.K., Algaier, J.W., \& Smith C.S., Comparison of Proanthocyanidins in commercial antioxidants: grape seed and pine bark extracts. J. Agric. Food Chem., 55, pp. 148-156, 2007.

[9] Vázquez, G., González-Alvarez, J., Freire, M.S., Fernández-Agulló A., Santos, J. \& Antorrena, G., Chestnut bur as a source of natural antioxidants. Chemical engineering transactions, 17, pp. 855-860, 2009. 